\title{
REVIEW
}

\section{Common data elements for spinal cord injury clinical research: a National Institute for Neurological Disorders and Stroke project}

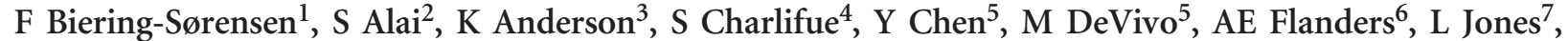 \\ N Kleitman ${ }^{7}$, A Lans ${ }^{2}$, VK Noonan ${ }^{8}$, J Odenkirchen ${ }^{9}$, J Steeves ${ }^{10}$, K Tansey ${ }^{11}$, E Widerström-Noga ${ }^{3}$ and \\ LB Jakeman ${ }^{9}$
}

Objectives: To develop a comprehensive set of common data elements (CDEs), data definitions, case report forms and guidelines for use in spinal cord injury ( $\mathrm{SCl}$ ) clinical research, as part of the CDE project at the National Institute of Neurological Disorders and Stroke (NINDS) of the US National Institutes of Health.

Setting: International Working Groups.

Methods: Nine working groups composed of international experts reviewed existing CDEs and instruments, created new elements when needed and provided recommendations for $\mathrm{SCl}$ clinical research. The project was carried out in collaboration with and crossreferenced to development of the International Spinal Cord Society (ISCoS) International SCI Data Sets. The recommendations were compiled, subjected to internal review and posted online for external public comment. The final version was reviewed by all working groups and the NINDS CDE team before release.

Results: The NINDS SCI CDES and supporting documents are publically available on the NINDS CDE website and the ISCoS website. The CDEs span the continuum of SCl care and the full range of domains of the International Classification of Functioning, Disability and Health.

Conclusion: Widespread use of CDEs can facilitate $\mathrm{SCl}$ clinical research and trial design, data sharing and retrospective analyses. Continued international collaboration will enable consistent data collection and reporting, and will help ensure that the data elements are updated, reviewed and broadcast as additional evidence is obtained.

Spinal Cord (2015) 53, 265-277 doi:10.1038/sc.2014.246; published online 10 February 2015

\section{INTRODUCTION}

There has been increasing interest in developing common data elements (CDEs) to facilitate start-up of clinical studies and to enable improved coordination, sharing and analyses of research data. ${ }^{1-4}$ Across the neuroscience community, this endeavor has been guided in large part by the National Institute of Neurological Disorders and Stroke (NINDS) of the National Institutes of Health (NIH). ${ }^{5}$ The NINDS CDE Project began in 2006 and has resulted in development of General CDEs that can be used across neurological diseases, and disease-specific CDEs, corresponding case report forms (CRFs) and guidance documents for 14 neurologic diseases and conditions to date, including traumatic brain injury, ${ }^{6,7}$ stroke, ${ }^{8}$ epilepsy, ${ }^{9}$ amyotrophic lateral sclerosis, ${ }^{10}$ Friedreich's ataxia ${ }^{11}$ and others. Central to this effort is the creation of meaningful common definitions to facilitate the organization, analysis, sharing and dissemination of data captured and recorded across studies. The stated goals of the NINDS CDE project $^{5,8,9}$ are:
- To disseminate standards for the collection of data from participants enrolled in studies of neurological diseases;

- To create easily accessible tools for investigators to collect study data;

- To encourage focused and simplified data collection to reduce the burden on investigators and practice-based clinicians to facilitate their participation in clinical research; and

- To improve data quality while controlling cost by providing uniform data descriptions and tools across NINDS-funded clinical studies.

The use of standardized CDEs can provide a number of benefits for investigators and the research community, including (1) rapid and efficient study start-up by enabling access to defined data elements and CRF templates; (2) improved patient safety by facilitating creation of common report templates for Data and Safety Monitoring Boards; (3) enriched data sharing and data aggregation using standard

${ }^{1}$ Department of Spinal Cord Injuries, Rigshospitalet and Glostrup Hospital, University of Copenhagen, Copenhagen, Denmark; ${ }^{2}$ The EMMES Corporation, Rockville, MD, USA; ${ }^{3}$ Miami Project to Cure Paralysis, Miller School of Medicine, University of Miami, Miami, FL, USA; ${ }^{4}$ Craig Hospital, Englewood, CO, USA; ${ }^{5}$ niversity of Alabama at Birmingham, Birmingham, AL, USA; ${ }^{6}$ Thomas Jefferson University Hospital, Philadelphia, PA, USA; ${ }^{7}$ Craig H. Neilsen Foundation, Encino, CA, USA; ${ }^{8}$ Rick Hansen Institute, Vancouver, BC, Canada; ${ }^{9}$ National Institute of Neurological Disorders and Stroke, National Institutes of Health, Bethesda, MD, USA; ${ }^{10}$ University of British Columbia and Vancouver Coastal Health, Vancouver, BC, Canada and ${ }^{11}$ Emory University and Atlanta VA Medical Center, Atlanta, GA, USA

Correspondence: Dr LB Jakeman, NIH/NINDS Repair and Plasticity, Neuroscience Center, MSC 9525, 6001 Executive Boulevard, Bethesda, MD 20852-9525, USA.

E-mail: Iyn.jakeman@nih.gov

The members of the SCI CDE Organizing Committee and the Working Group are listed before references.

Received 23 September 2014; revised 4 December 2014; accepted 25 December 2014; published online 10 February 2015 
definitions and forms; and (4) adoption of common outcome measures that may be relevant across neurological diseases. A centralized website including the data standards and accompanying tools is maintained by the NINDS at (http://www.CommonDataElements.ninds.nih.gov).

CDEs have been developed for each of the neurological disease areas using a common iterative approach. An initial organizing committee of disease experts is convened to define the specific domains for data collection across the disease area. Within each domain, this group then identifies a team of experts to review the state of the field and choose and define the instruments and data elements used for clinical studies. NINDS maintains a hands-off role, enabling the experts to identify the key topics and instruments while providing administrative support and guidance as needed. ${ }^{5}$

Development of the CDEs for spinal cord injury (SCI) was somewhat unique compared with that of other disease sets with regard to the working process and the breadth of content. From the start, the SCI $\mathrm{CDE}$ process included an active collaboration with an existing international effort to create clinically directed International SCI Data Sets by expert working groups. ${ }^{12,13}$ The International SCI Data Set project began in 2002 to provide 'a common language among SCI centers worldwide'. There are currently 21 completed International SCI Data Sets that provide a working resource of guidelines and data collection forms for widespread use by the international SCI clinical community. The International SCI Data Sets are updated regularly by a process that includes review and approval by the International Spinal Cord Society (ISCoS) and the American Spinal Injury Association (ASIA), representing the two major international professional societies of SCI clinicians and scientists. The NINDS CDE and ISCoS International SCI Data Set projects have overlapping but distinct goals. Yet, because of the active collaboration approach, they use standard variable names and a common database structure. ${ }^{14}$ To continue to provide open access to both initiatives, the approved International SCI Data Sets, organized by topic and listed by date of approval, are publically available on both the ISCoS website (http://www.iscos.org.uk/international-sci-data-sets) and the NINDS SCI CDE website (http://www. commondataelements.ninds.nih.gov/SCI.aspx).

In addition to the cooperative international process, the SCI CDEs are also somewhat unique because they encompass an exceptionally wide breadth of content. SCI can disrupt long ascending and descending spinal pathways as well as segmental and autonomic neural circuitry. Therefore, the consequences and relevant outcome measures in SCI research can involve biological functions extending below, at and above the neurological level of the injury. In addition, although the spinal cord level and severity of injury can determine the degree of sensory and motor impairment, SCI also affects other activities of daily living as a result of impaired function of many body systems (for example, bladder and urinary, bowel and gastrointestinal, sexual, respiratory, cardiovascular and thermoregulatory systems). Some other health and quality of life (QOL) consequences and complications common following SCI include the development of pressure ulcers, infections, altered bone and muscle composition, impaired mobility and participation, psychosocial distress and persistent pain. The expert teams also recognized that neurological and functional assessments are sometimes insufficient and can be enhanced by established electrodiagnostics, and that modern imaging techniques that visualize the damaged spinal cord parenchyma now play a critical decision support role in the early assessment and management of SCI. Thus, the working groups agreed that a comprehensive range of outcomes and a correspondingly large number of clinical research CDEs were needed in this field.
The overarching goal of the participants in the SCI CDE project was to provide recommendations to assess all domains of the World Health Organization International Classification of Functioning, Disability and Health (ICF), including personal factors and body structures and functions, as well as activity, participation and environmental factors (WHO, 2001). ${ }^{15}$ The selection and recommendation of data elements and instruments were also designed to consider wide variation in the severity of injury, the time of encounter along the SCI continuum (acute vs chronic injuries) as well as the time of onset and etiology of nontraumatic SCI.

\section{MATERIALS AND METHODS}

\section{Development of NINDS CDEs for SCI}

The SCI CDE project began in 2012 as part of the larger NINDS CDE effort. An organizing committee with representatives from ISCoS, ASIA and the NINDS was convened at an international meeting. The committee invited SCI experts to form working groups (WGs), each composed of five to seven members with knowledge and experience relevant to the primary clinical SCI domains. These experts included clinicians, clinical researchers, clinical trial experts and representatives from industry as well as private and public funding organizations. The WGs were initially organized into the following domains: (1) Demographics; (2) Care; (3) Neurological outcomes; (4) Functional outcomes; (5) Participation and QOL; (6) Electrodiagnostics; and (7) Imaging. These domains were chosen by discussion and consensus of the initial organizing committee, with the understanding that the process would likely unveil important areas that would require further consideration. Indeed, soon after starting, an additional WG was created to address Pain outcomes, and after several meetings, a subgroup was recruited to specifically address Psychological outcome measures, bringing the total to nine WGs (see Acknowledgments). The Chair of each WG, together with the organizing committee, constituted an advisory team that communicated throughout the development phase to coordinate goals and to identify shared solutions. Each WG was tasked with identifying existing data elements and/or assessment instruments in the assigned domain and to provide guidelines and recommendations for their use in SCI clinical studies. The WGs developed CRFs by selecting the most relevant items from existing CDEs and instruments, or identified and recommended the use of copyrighted instruments, or, when it was necessary, they developed new CDEs, instruments and recommendations de novo. Brief details of how this was done in the individual groups are described below.

\section{Terminology of the NINDS CDEs}

Consistent with guidance across the NINDS CDE project, the WGs were also charged with classifying each of the recommended SCI CDEs and instruments as 'Core', 'Supplemental' or 'Exploratory' according to the following definitions:

1. Core CDE: a data element identified for use by all SCI studies, and strongly encouraged for use by any SCI study. These are few in number, and they are used to provide consistent data items across all studies, especially regarding basic participant information. The Core SCI CDEs also include those CDEs defined by the NINDS as 'Core for All Neurological Diseases'.

2. Supplemental CDE: a data element that is recommended for collection and use for a significant proportion of SCI clinical research studies, but the relevance for each study depends upon either the study design (for example, clinical trial, cohort study, acute or chronic, phase I/II or III and so on) or the type of research or intervention (for example, inpatient vs community or survey, epidemiology vs rehabilitation). Supplemental CDEs constitute the majority of the recommendations of the NINDS project as a whole and the majority of SCI CDEs. Within the Supplemental CDEs, the WGs categorized those that are most highly recommended for specific types of studies as 'Supplemental/Highly Recommended'. This designation was used for CDEs of exceptionally high relevance, with strong validity and psychometric properties and wide support from the international SCI clinical community.

3. Exploratory CDE: a data element that may fill a current gap in the $\mathrm{CDE}$ panel, but which requires further validation before reaching a consensus 
recommendation. For the SCI WGs, CDEs were classified as 'Exploratory' either because they lacked validity testing, robust psychometrics or, despite widespread use for other conditions, they lacked evidence of validity in SCI research studies at the time of the initial CDE development.

\section{A conceptual framework}

Managing the depth and breadth of SCI data required an organizational framework to help visualize the essential data categories and to allow WG autonomy while minimizing gaps and overlapping efforts. The goal of the approach was to maintain the commitment to include the full continuum and severity of SCI and encompass the complete range of ICF domains. The Care WG thus built on the experience of the NINDS traumatic brain injury CDE project, ${ }^{6}$ and conceived a working map to address the CDE concept organization (Table 1, and see Care WG below). Each stage along the SCI care continuum (left column) was associated with the relevant ICF domains. The main categories were defined and then the concept domains were organized, using descriptive terms consistent across the NINDS CDEs http://www. commondataelements.ninds.nih.gov/SCI.aspx\#tab $=$ Data_Standards. Finally, SCI-specific subdomains were identified and the resulting topics were distributed among the WGs for review and recommendations.

\section{Review process}

After compiling the CDEs and definition tables, recommendations, CRFs and guidelines from each of the WGs, the draft documents were disseminated for internal review by the full panel of WG experts and the NINDS CDE project team. Changes and/or clarifications were made as appropriate. The internally approved documents were then introduced and released to the public in May 2014 as Version 0.0 , and were made widely available for external review by downloading from the NINDS CDE website, as well as through a link from the ISCoS website. To encourage public input, directed notices of the review period and instructions were sent to SCI clinicians and researchers, industry representatives, research center directors and SCI organizations, including research foundation leaders and consumers. Members of ISCoS were informed via a newsletter, and a formal announcement was made at the 2014 ASIA Annual Scientific Meeting. Interested parties provided comments that were then compiled and discussed by each of the WGs and further revisions were made. Version 1.0 of the NINDS SCI CDEs was released on June 30 and revised on 30 August 2014.

\section{RESULTS}

\section{WG process}

Each of the WGs proceeded with slightly different approaches that were largely dependent on the status of existing data standards and elements. For example, the Demographics and Care WGs covered domains with the most crossover to other clinical conditions and neurological disease, and, thus, they started with and selected data elements from many existing individual CDEs and added a few available instruments that were most appropriate for SCI studies. Both the Neurological and Functional outcomes WGs were also required to critically evaluate the current reliability and validity of historically accepted and newer SCI clinical outcome measures to make recommendations for future studies. The Participation and QOL WG, the Pain WG and the Psychological outcomes WG each covered domains that are less well established for SCI studies, but instead draw from a wide array of current and validated assessment tools outside of the SCI clinical area. Finally, the Electrodiagnostics and Imaging WGs developed entirely new CDEs, CRFs and clinical instruments, as there was very little in the way of established outcome measures or guidelines for use in SCI studies.

To select the CDEs for consideration, each WG had a chairperson who, in cooperation with the NINIDS CDE project staff, initially collected potential CDEs, measures and tools for discussion in the group. In monthly WG meetings, individuals in each group were typically assigned subdomains in their area of expertise, and researched existing outcome measures and tools for evidence of validity, reliability and acceptance in the community. All items were discussed and the decisions of which items to include and how they should be classified were made in subsequent teleconference calls by consensus of all WG members. All procedural or cross-WG questions or concerns were brought up for review by the full organizing committee.

\section{WG recommendations:}

The SCI CDE Version 1.0 release includes over 1150 distinct CDEs, many of which are compiled into template CRFs. As an example, the CRF used to collect data elements on the history of injury is shown in Figure 1. The final CDEs include seven Core elements that are required for all NINDS CDE sets, as well as two SCI-specific Core CDEs, the date and etiology of injury and one Core instrument, the International Standards for Neurological Classification of Injury (ISNCSCI). There are eight Supplemental instruments classified as Highly Recommended for use in clinical SCI research whenever appropriate (each instrument includes several individual CDEs). The remainder of the CDEs and instruments are classified as either Supplemental or Exploratory. The detailed list and breakdown of all of the recommended CDEs and instruments by WG domain and classification is provided in Table $2 .{ }^{16-37}$ This table will be available on the main NINDS SCI CDE website page and updated as indicated by future review recommendations. Specific considerations of each of the WGs are described briefly in the sections below.

Demographics WG. Demographic and socioeconomic CDEs have been studied extensively and are cross-referenced across many disease areas. This WG reviewed the General NINDS CDEs and then focused on the common variables or measures included in existing SCI registries and clinical studies regarding demographics, socioeconomic status, injury etiology and vital status. Particular emphasis was placed on the existing elements in the International Spinal Cord Injury Core Data Set, ${ }^{16}$ the Spinal Cord Injury Model Systems (SCIMS) Database $\mathrm{e}^{38,39}$ and new elements that are in consideration for inclusion in the International Spinal Cord Injury Socio-Demographic Data Set that is currently in development. Criteria for inclusion of the demographics CDEs for SCI included utility and perceived acceptability to both US and international research studies. The NINDS Core Demographics CDEs for all diseases were also included in the resulting CRF.

Care WG. Given the wide range of possible SCI studies and varied care history of potential participants, this WG had the most complex and largest number of subdomains and existing CDEs to consider. The overarching structure they adapted for categorizing the CDEs into subdomains was modeled largely after work conducted to develop data elements for traumatic brain injury. ${ }^{6}$ The Concept Domains covered were participant and family history, history of injury and prehospital care, hospital management, clinical assessments and examinations, and treatments, interventions and therapies (Table 1). To prevent overlap of efforts, the Care WG focused on nonneurological body systems, and did not make recommendations for the key clinical assessments and subdomains covered by the other WGs, such as the neurological and functional assessments, pain or psychological assessments, electrodiagnostics or imaging. They did review and provide recommendations regarding instruments to assess sleep. 
Table 1 Data element structural map: data concepts spanning the Care Continuum and WHO-ICF domains

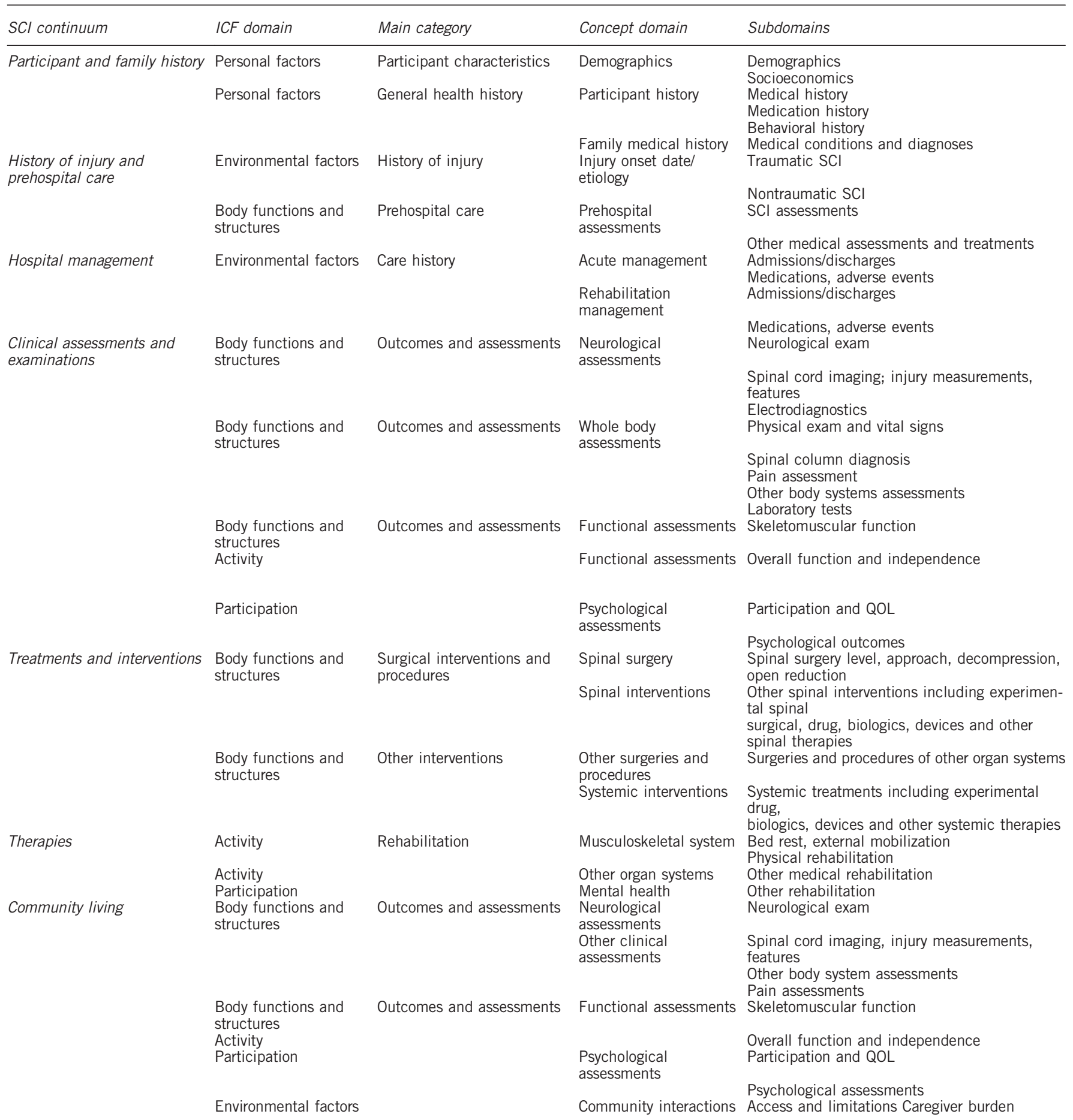

Abbreviations: SCI, spinal cord injury; WHO-ICF, World Health Organization International Classification of Functioning, Disability and Health. QOL, Quality of Life.

For the Care Domain, the CDEs found within the International SCI Data Sets were aptly used as the foundation for many of the recommendations, as these were already developed and approved by International SCI experts and represent clinical data sets deemed most relevant to Clinical Care and Assessment factors across the SCI spectrum. ${ }^{16-37}$ These CDEs were supplemented by items from SCI registries such as the Rick Hansen SCI Registry ${ }^{40}$ and the North American Clinical Trial Network SCI Registry, ${ }^{41}$ as well as other NIH
CDEs and published outcome measures. The NINDS General Core CDEs for Medical History using the SNOMED CT Code and/or a textbased Medical History Term were included in the Medical History CRF to provide consistent reporting across all diseases.

Neurological outcomes WG. This WG emphasized that accurate characterization of the spinal cord level and severity of SCI are fundamental to the prognosis and progress of any recovery associated 


\section{History of Injury}

[Study Name/ID pre-filled]

Site Name:

Subject ID:

\section{Injury Timeframe}

1. *Date of Visit: YYYY/MM/DD

2. *Date of injury: YYYYMMDD

Time of injury: HH:MM:SS

Unknown

3. Timeframe of onset of non-traumatic spinal cord injury

$\square$ acute ( $\leq 1$ day)

$\square$ sub-acute ( $>1$ day but $\leq 7$ days)

$\square$ prolonged ( $>7$ days but $\leq$ month)

$\square$ lengthy (> 1 month)

\section{Injury Etiology}

4. *Injury etiology (with descriptive non-traumatic etiology):

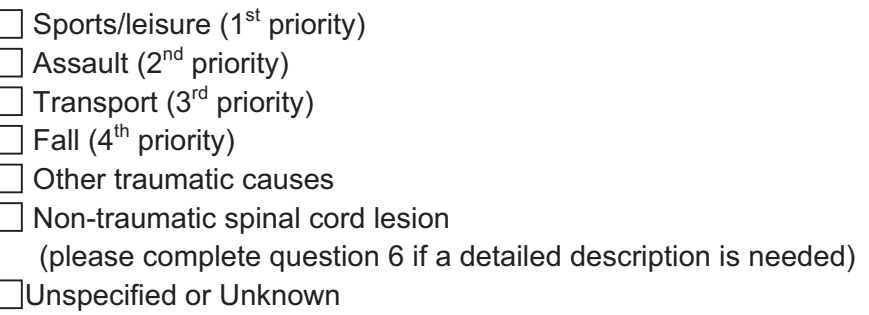

5. latrogenic role in etiology:

$\square$ No $\square$ Yes $\square$ Unknown

Figure 1 Example of a case report form, in this case a form to record elements related to the history of injury. The forms directly support the underlying common data structure, and each form includes specific user instructions to enable permissible and valid data entry. Asterisks * are used to designate those elements that are considered Core, to be collected in all spinal cord injury studies.

with a standard of care or therapeutic intervention, especially over the first few months after SCI. The International Standards for the Neurological Classification of Spinal Cord Injury (ISNCSCI) is recognized as the current worldwide standard instrument for the examination and classification of neurological sensorimotor impairment after SCI and is an essential assessment tool. ${ }^{35}$ The ISNCSCI was thus designated as a Core instrument, required for all SCI clinical studies or intervention trials.

Notably, this WG did not recommend the use of grades (A-E) to describe sensory and motor preservation according to the ASIA Impairment Scale (AIS). They noted that in prior studies, improvement of two AIS grades (for example, AIS-A to AIS-C) has been recommended and/or used as a clinical trial end point or response criterion. ${ }^{42-45}$ However, no experimental treatment to date has been shown to be effective based on this end point. ${ }^{42}$ Furthermore, they noted that in some situations, a two-grade AIS change can represent an improvement that may not be functionally meaningful.

Neurological reflex tests are also valuable for the accurate diagnosis and classification of neurological impairment and can be used to distinguish physiological loss of supraspinal drive from similar loss of function that is due to segmental injury to motor efferents. The NINDS Myotatic Reflex Scale ${ }^{46}$ was recommended for evaluating reflexes in SCI studies. In addition, the Modified Ashworth Scale, Tardieu Scale, Spinal Cord Assessment Tool for Spastic Reflexes (SCATS), Penn Spasm Frequency Scale and/or the Pendulum Test were each recommended for use in quantifying spasticity. Additional guidelines for selection and use of these neurological outcome measures and further references and copyright information can be found on the NINDS CDE website.

Functional outcomes WG. The Functional outcomes WG reviewed many sources, including existing SCI functional instruments, NINDS CDEs from other diseases and the International SCI Data Sets. Those determined to not be measuring true function or deemed inappropriate for SCI clinical research were eliminated. The selection of measures was then narrowed down to include only those with existing psychometric data in SCI. The selected measures were categorized into three subdomains: (1) Gait and Balance, (2) Upper Extremity and (3) Overall Function (Table 2). In addition to reviewing these sources and the existing literature for each measure, current functional outcome measure recommendations from key organizations were adopted and referenced as appropriate. These included the Spinal Cord Injury Rehabilitation Evidence (SCIRE) website (http://www.scireproject.com/), the SCI EDGE task force website (Evidence Database to Guide Effectiveness; a project of the American Physical Therapy Association, APTA, Neurology Section; http://www.neuropt.org/professional-resources/neurology-section-outcome-measures-recommendations/spinal-cord-injury) and the Rehabilitation Measures Database website (http://www.rehabmeasures.org/rehabweb/rhaboutus.aspx).

The time post injury and level/severity of SCI are necessary qualifiers for selection of the recommended functional outcome measures. For this reason, there are no functional measures that are appropriate for all SCI studies and, thus, no Core elements or 
Table 2 Summary of National Institute for Neurological Disorders and Stroke (NINDS) spinal cord injury common data elements (CDEs) and instruments: listed by working group-assigned domains and subdomains

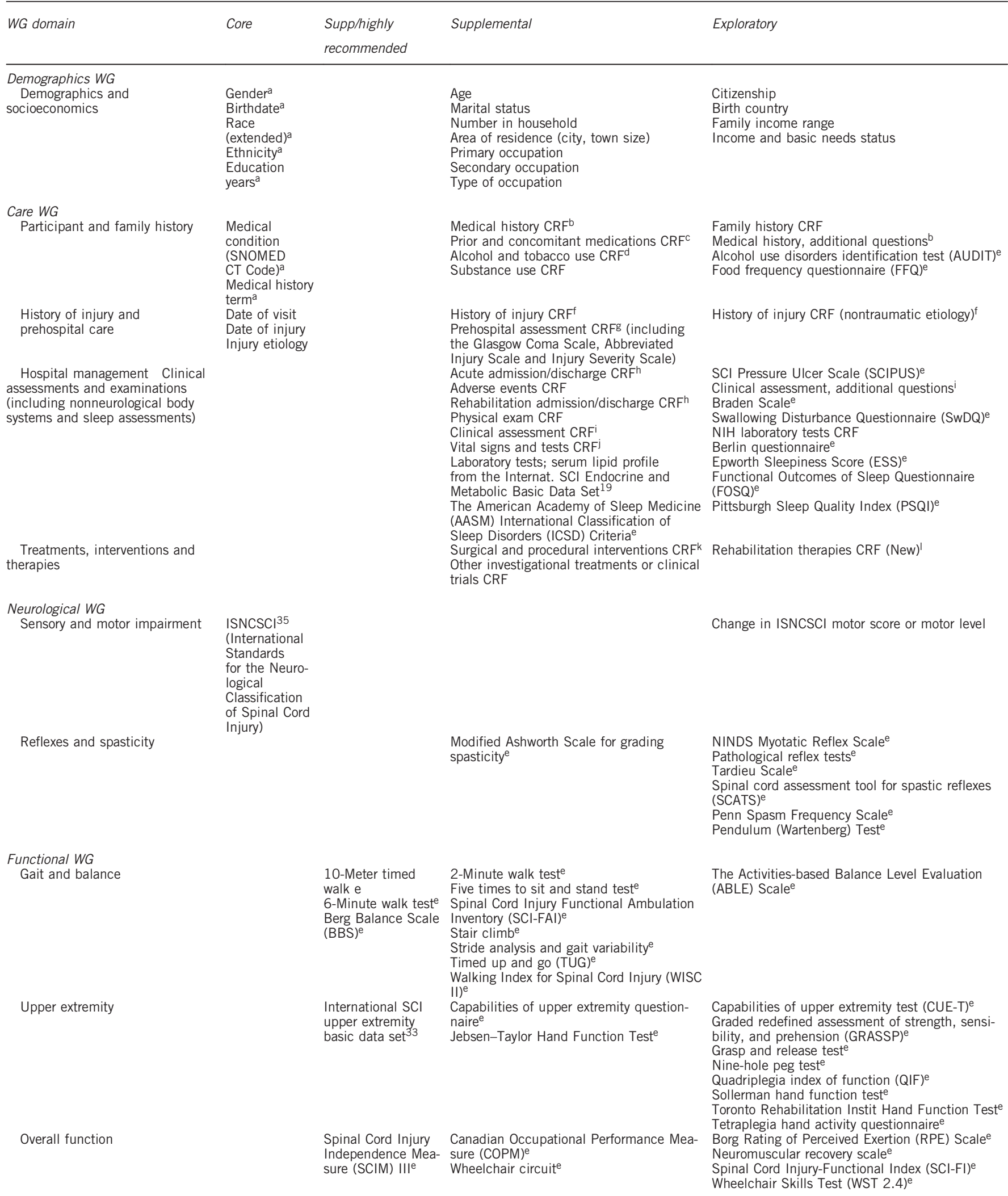


Table 2 (Continued)

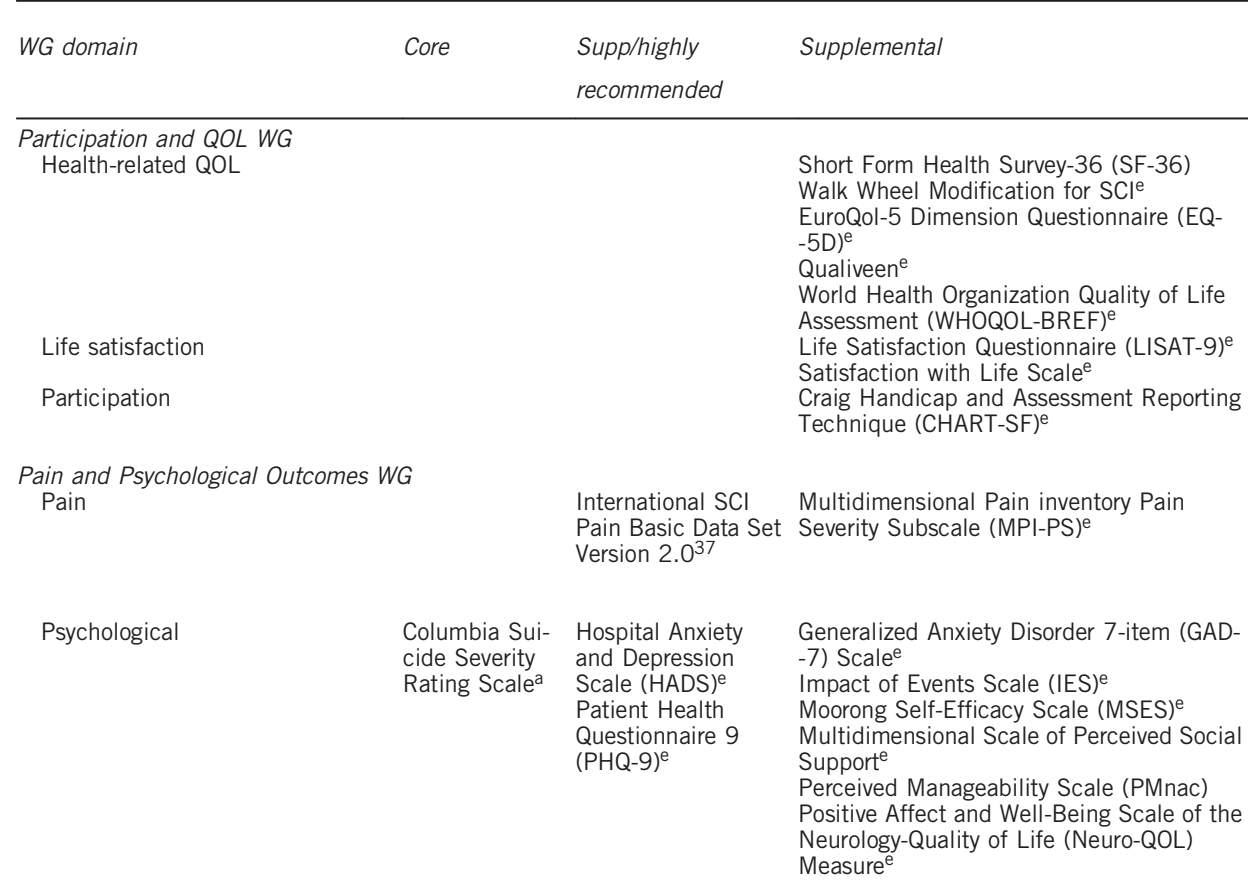

\section{Electrodiagnostics $W^{m}$ \\ Motor tests \\ Nerve and muscle \\ Sensory tests}

\section{Pain Basic Data Set Severity Subscale (MPI-PS)}

Generalized

Multidimensional Scale of Perceived Social

Support

Positive Affect and Well-Being Scale of the

Measure $^{\mathrm{e}}$

Motor evoked potentials (MEPS) CRF (New) Brain motor control assessment CRF (New) Peripheral nerve studies CRF (New) Quantitative sensory testing (QST) CRF (New)

Sympathetic skin response CRF (New) Sensory evoked potentials CRF (New)

Imaging WG
Douleur Neuropathique $4(\mathrm{DN} 4)^{\mathrm{e}}$

painDETECT ${ }^{\mathrm{e}}$

Neuropathic Pain Questionnaire (NPQ) Neuropathic Pain Symptom Inventory (NPSI) Pain Quality Assessment Scale (PQAS)
Magnetic resonance imaging $\mathrm{CRF}(\mathrm{New})^{\mathrm{n}}$ Diffusion tensor imaging (DTI) CRF (New)

Exploratory

Spinal cord injury-quality of life (SCI-QOL)e

Quality of Life Index (QLI) -SCI Version International SCI Quality of Life Basic Data Set ${ }^{36}$
Electrical perceptual threshold CRF (New)

CT angiography (CTA), MR angiography (MRA), magnetization transfer (MT), functional MR ( $\mathrm{FMRI}$ ), perfusion, spectroscopy (MRS), myelin water fraction, diffusion kurtosis imaging (DKI)

Abbreviations: CDE, common data element; CRF, case report form; SCI, spinal cord injury; SNOMED CT, Systematized Nomenclature of Medicine-Clinical Terms; Supp, Supplemental; WG, working group.

The categories and concept domains from Table 1 were divided among the WGs for detailed recommendations, with attention paid to minimizing overlap and gaps as described in the text. This table lists each of the elements and instruments that were recommended by the expert WGs as well as the CRF that were created by the WG from non-copyrighted sources.

'(New)' indicates that CRFs and recommendations were created de novo by the WG.

Many of the CRFs prepared from recommendations of the Care WG included individual CDEs selected from the International Spinal Cord Society (ISCoS) International SCI Data Sets. The footnotes document the source of CDEs derived from the ISCoS International SCI Data Sets where space in the Table was not sufficient.

aRequired as NINDS Core Elements for use in all neurological diseases and conditions.

bThe Medical History CRF contains Supplemental and Exploratory CDEs, including date (from the International SCI Core Data Set ${ }^{16}$ ) and cause(s) of death and body systems function questions (from the International SCI Cardiovascular Function Basic Data Set, ${ }^{17}$ the International SCI Pulmonary Basic Data Set, ${ }^{18}$ the International SCI Endocrine and Metabolic Function Basic Data Set, ${ }^{19}$ the International SCI Musculoskeletal Basic Data Set, ${ }^{20}$ the International SCI Lower Urinary Tract Function Basic Data Set ${ }^{21}$ and the International SCI Bowel Function Basic Data Set ${ }^{22}$ ). ${ }^{\mathrm{C} T h e}$ Prior and Concomitant Medicine CRF contains CDEs selected from the International SCI Lower Urinary Tract Function Basic Data Set; 21 the International SCI Bowel Function Basic Data Set:22 the International SCI Cardiovascular Function Basic Data Set; ${ }^{17}$ and the International SCI Musculoskeletal Basic Data Set. ${ }^{20}$

dThe Alcohol and Tordovascular Function Basic Data Set; ${ }^{17}$ and the International SCI Musculoskeletal Basic Data Set. ${ }^{20}$ Set. ${ }^{18}$

eOne or more recommended CDEs come from copyrighted instruments. Copyright information is included on the NINDS-CDE website.

fThe History of Injury CRF contains Supplemental and Exploratory CDEs from the International SCI Core Data Set, ${ }^{16}$ the International Non-Traumatic SCI Basic and Extended Data Sets ${ }^{23}$ and the International SCI Spinal Column Injury Basic Data Set. ${ }^{24}$

gThe Prehospital Assessment CRF contains CDEs selected from the International SCI Core Data Set. ${ }^{16}$

hThe Acute Admission/Discharge CRF and Rehabilitation Admission/Discharge CRF both contain items from the International SCI Core Data Set. ${ }^{16}$

iThe Clinical Assessment CRF contains CDEs selected from the following International SCI Data Sets: Supplementary CDEs were selected from the International SCI Spinal Column Injury Basic Data Set; ${ }^{24}$ the International SCI Pulmonary Function Basic Data Set; ${ }^{18}$ the International SCI Cardiovascular Function Basic Data Set; ${ }^{17}$ the International Lower Urinary Tract Basic Data Set; ${ }^{21}$ all CDEs from the International SCI Urinary Tract Infection Basic Data Set. 25 and selected CDEs from the International SCI Bowel Basic Data Set, 22 the International SCI Skin and Thermoregulation Function Basic Data Set, ${ }^{26}$ the International SCI Musculoskeletal Basic Data Set, 20 the International SCI Endocrine and Metabolic Basic Data Set, ${ }^{19}$ the International SCI Male Sexual Function Basic Data Set, ${ }^{27}$ and the International SCI Female Sexual and Reproductive Function Basic Data Set; ${ }^{28}$ Exploratory CDEs were selected from questions from the International SCI Bowel Function Extended Data Set. ${ }^{29}$

iThe Vital Signs and Tests CRF includes all CDEs from the International SCI Urinary Tract Imaging Data Set, ${ }^{30}$ and selected CDEs from the International SCI Endocrine and Metabolic Basic Data Set $^{19}$ (height and weight), the International Cardiovascular Function Basic Data Set, ${ }^{17}$ the International Skin and Thermoregulation Basic Data Set ${ }^{26}$ (temperature), the International SCI Pulmonan Function Basic Data Set ${ }^{18}$ (pulmonary function tests) and all CDEs from the International SCI Urodynamic Basic Data Set. ${ }^{31}$

${ }^{k}$ Surgical and Procedural Interventions CRF includes all CDEs from the International SCI Spinal Interventions and Surgical Procedures Basic Data Set ${ }^{32}$ and selected CDEs from the International Lower Urinary Tract Function Basic Data Set-surgical procedures, ${ }^{21}$ the International SCI Skin and Thermoregulation Basic Data Set-surgical procedures, ${ }^{26}$ the International SCI Musculoskeletal Basic Data Set-surgical procedure, ${ }^{20}$ the International SCI Bowel Basic Data Set-surgical procedures ${ }^{22}$ and the International SCI Upper Extremity Basic Data Set-surgical procedures. ${ }^{33}$ 'Rehabilitation therapies: this CRF was based largely on the SCIRehab Project. ${ }^{34}$

mElectrodiagnostics WG recommendations: detailed recommendations for these CDEs are provided in Table 3.

"Imaging WG recommendations: recommended magnetic resonance imaging (MRI) values are listed in Figure 2a, including technical specifications, spinal injury type, spinal canal and cord measurements, $\mathrm{SCl}$ features and locations and chronic $\mathrm{SCl}$ features.

instruments were recommended by this WG. Based on validation and widespread clinical acceptance, the 10-Meter Walk Test and 6-Minute Walk Test were designated as Supplemental/Highly Recommended instruments for all studies evaluating gait; the Berge Balance
Scale for those evaluating balance; the International SCI Upper Extremity Basic Data $\mathrm{Set}^{33}$ for descriptive characterization of upper extremity function and the Spinal Cord Independence Measure III for overall function. The remaining validated instruments and tools were 
designated as Supplemental. There were also a number of newer outcome measures designed specifically for SCI functional assessment; these were categorized as Exploratory as there is still a significant amount of psychometric testing required for validation. References for the copyrighted instruments are available on standard forms found on the NINDS SCI CDE website.

Participation and QOL WG. This WG focused on identifying potential instruments from the literature and clinical expertise that address three principle areas relevant to SCI outcome: health-related QOL, life satisfaction and participation. Specific preference was given to those measures that (1) have been extensively used in SCI, (2) could be applicable to both the acute and chronic situations or (3) were in an extensive phase of development specific to SCI that encouraged inclusion. In each instance, timing of the assessments was deemed critical. Specifically, during the acute rehabilitation stage, perceptions of health-related QOL and life satisfaction are likely to be influenced by adjustment to injury, acute hospitalization, recovery from concomitant injuries and other factors. In contrast, participation is difficult to assess in the acute stage and is better conceptualized once an individual with SCI has returned to the community and begins to reintegrate into life activities. Seven copyrighted questionnaire instruments were recommended as Supplemental, whereas three that require further validation were listed as Exploratory. In all cases, an emphasis was placed on those instruments and tools that are widely used for health assessment internationally, including the EuroQOL, WHOQoLBREF and SF-36 Quality Metrics instruments. One notable instrument that is recommended for SCI studies is the SCI-QOL or spinal cord injury multidimensional QOL instrument. This was developed using item response theory and computer adaptive testing concepts from the NIH PROMIS ${ }^{47}$ and Neuro-QOL ${ }^{48}$ tools, but SCI-QOL ${ }^{49}$ is adapted specifically for use in the SCI population.

Pain WG. The Pain WG selected evidence-based instruments using both preexisting frameworks and specific pain-relevant domains. Determination of utility was made based on availability of published psychometric data in the SCI population. Issues unique to SCI, for example, multiple consequences of SCI and the presence of several concomitant pains, were considered in the development of the SCI pain assessment instruments.

The Pain WG recommended use of the International SCI Pain Basic Dataset (ISCIPBDS ${ }^{37}$ ) and the International SCI Pain Classification (also part of the ISCIPBDS ${ }^{50,51}$ ) for assessing pain. All domains included in the ISCIPBDS were classified as 'Supplemental/Highly Recommended'. The ISCIPBDS is intended to be used in its entirety and was endorsed as such by major SCI (ASIA, ISCoS, Academy of Spinal Cord Injury Professionals) and pain organizations (American Pain Society and the International Association for the Study of Pain) and by individual reviewers. Some domains include several recommended measures, and hence the choice of specific measure will be dependent on the purpose of the study, similar to the principles of PROMIS. ${ }^{47}$ Notably, the ISCIPBDS is designed to address the presence of multiple pains by evaluating each individual pain problem separately.

Psychological outcomes WG. Late into the development process, a recognized gap in the list of assessment and outcomes led to the development of the ninth WG, focused on Psychological status or Psychological outcomes. After reviewing the available instruments, this WG recommended the Hospital Anxiety and Depression Scale ${ }^{52}$ and the Patient Health Questionnaire ${ }^{53,54}$ as Supplemental/Highly Recommended for assessing SCI-related psychological status. All other recommended measures reviewed by the group were classified as Supplemental or Exploratory, where Exploratory measures were those that need further studies to establish their psychometric properties and thus their respective utility for SCI.

Electrodiagnostics WG. The Electrodiagnostics WG had the task of defining sensitive and reliable tests for physiological assessments, with no preexisting lists or resources for commonly used tests to choose from. The WG thus developed de novo test names and descriptions of the purpose of each, providing guidelines for the level or duration of SCI for the test, creating recommendations for required test equipment and cost as well as needed training, defining the parameters to be measured or calculated, making suggestions for data analysis or interpretation and defining potential pitfalls and any relationship between the test and other outcomes. The committee members divided up the tasks for description and then associated CRFs were developed or edited from other CDE efforts. An essential component of the online posted Electrodiagnostics documents is a general introduction to the set of tests, written to explain the rationale for which tests to use and for what purposes. This introduction emphasizes the difference between tests that measure the conduction of electrical signals across the level of SCI (relatively more established) and those that assess processing of those signals by neural circuitry below the level of injury (less established) as well as describes other tests of signal processing that are currently under development. Table 3 gives an overview of the electrodiagnostics recommendations.

Imaging WG. The Imaging WG also developed recommendations in an area where no previous guidelines existed. The WG evaluated a wide range of existing imaging approaches and techniques in common clinical use for spinal trauma and SCI, including radiography, computed tomography and magnetic resonance imaging (MRI). The CRFs began as a working document that was derived from an amalgamation of anatomic MRI features that have been used successfully in the published literature, and some of the technical information was adapted directly from the traumatic brain injury imaging CDEs. Key factors that can have a direct effect on the imaging features of SCI were taken into consideration including: injury to imaging time interval, the use of methylprednisolone in the acute period, injury acuity or chronicity and whether instrumentation was placed before imaging. In addition, instrumentation is an obstacle to overall image quality; even nonferrous instrumentation can significantly hamper visualization of the SCI.

Because MRI possesses the unique capability to noninvasively depict the damaged substructure of the spinal cord, the WG advocated that Imaging CDEs for SCI studies going forward be derived only from MRI data sets. In contrast, radiography and computed tomography are used primarily to visualize the extent of bony injury. The resulting MRI CRF was developed to represent anatomic findings that are routinely discernible on commercial MRI platforms at 1.5 Tesla and above (Figure 2). ${ }^{55,56}$ In addition, the WG included diffusion tensor imaging data elements, with the rationale that this technology has matured sufficiently and that it is available and feasible with most modern clinical systems. ${ }^{57}$ The CDEs were divided into discrete sections that included: technical parameters, spinal injury characteristics, spinal canal and cord measurements, SCI features and locations and chronic SCI features. Technical parameters (protocols) for obtaining generic diffusion tensor imaging of the spinal cord were included as well as a standardized reporting system for diffusion tensor imaging. 
Table 3 Electrodiagnostics tests

\begin{tabular}{|c|c|c|c|c|c|}
\hline Test & Assessment & $\begin{array}{l}\text { Injury } \\
\text { level }\end{array}$ & $\begin{array}{l}\text { Injury } \\
\text { severity }\end{array}$ & $\begin{array}{l}\text { Injury stage } \\
\text { (acute-chronic) }\end{array}$ & Comments \\
\hline Nerve conduction studies (NCS) & $\begin{array}{l}\text { Peripheral nerve or root } \\
\text { involvement }\end{array}$ & C2-S3 & AIS A-E & All & $\begin{array}{l}\text { Perform across level of potential } \\
\text { lower motor neuron (LMN) damage }\end{array}$ \\
\hline Electromyography (EMG) & $\begin{array}{l}\text { Lower motor neuron, } \\
\text { peripheral nerve, muscle } \\
\text { function }\end{array}$ & C2-S3 & AIS A-E & All & $\begin{array}{l}\text { Perform across (and below) level of } \\
\text { potential LMN damage }\end{array}$ \\
\hline Quantitative sensory testing (QST) & $\begin{array}{l}\text { Sensitivity of clinically } \\
\text { impaired sensation }\end{array}$ & C2-S3 & AIS A-E & $\begin{array}{l}\text { All, qualified: } \\
\text { Participant must report } \\
\text { stimulus intensity }\end{array}$ & $\begin{array}{l}\text { Multiple measures to ensure } \\
\text { validity with day-to-day variation } \\
\text { Not an electrodiagnostic test }\end{array}$ \\
\hline Electrical perceptual thresholds (EPTs) & Cutaneous sensory perception & C2-S3 & AIS A-E & $\begin{array}{l}\text { All, qualified: } \\
\text { Participant must report } \\
\text { sensitivity to stimulus }\end{array}$ & $\begin{array}{l}\text { Exploratory, corresponds well } \\
\text { with SSEP, but not yet used widely }\end{array}$ \\
\hline $\begin{array}{l}\text { Somatosensory evoked potentials (SSEPS), } \\
\text { can be done by dermatome (dSSEPs) }\end{array}$ & $\begin{array}{l}\text { Large diameter fibers, spinal } \\
\text { dorsal column conduction }\end{array}$ & C2-S5 & $\begin{array}{l}\text { AIS A-E: } \\
\text { Likely absent in A } \\
\text { before intervention }\end{array}$ & All & $\begin{array}{l}\text { Widely used Amplitude varies, } \\
\text { latency is more useful measure } \\
\text { Sensitive to functional deterioration }\end{array}$ \\
\hline $\begin{array}{l}\text { Contact heat/laser evoked potentials } \\
\text { (CHEPs, LEPs) }\end{array}$ & $\begin{array}{l}\text { Small diameter fibers, } \\
\text { spinothalamic tract } \\
\text { conduction }\end{array}$ & C2-S5 & $\begin{array}{l}\text { AIS A-E: } \\
\text { Likely absent in A } \\
\text { before intervention }\end{array}$ & $\begin{array}{l}\text { All, qualified: } \\
\text { Participant must be } \\
\text { alert and attentive }\end{array}$ & $\begin{array}{l}\text { Beginning use in clinical applica- } \\
\text { tions in } \mathrm{SCl}\end{array}$ \\
\hline $\begin{array}{l}\text { Motor evoked potentials (MEPs) using } \\
\text { transcutaneous magnetic stimulation (TMS) }\end{array}$ & $\begin{array}{l}\text { Conduction of corticospinal } \\
\text { innervation to motor } \\
\text { neurons of targeted } \\
\text { muscle(s) }\end{array}$ & $\mathrm{C} 2-\mathrm{T} 12$ & $\begin{array}{l}\text { AIS A-E: } \\
\text { Likely absent in A/B } \\
\text { before intervention }\end{array}$ & All & $\begin{array}{l}\text { False negatives are possible } \\
\text { Consider facilitation techniques if } \\
\text { indicated }\end{array}$ \\
\hline $\begin{array}{l}\text { Brain motor control assessment } \\
\text { (BMCA) (arm, trunk, leg EMG to } \\
\text { supraspinal influence) }\end{array}$ & $\begin{array}{l}\text { Motor control, across } \\
\text { muscles } \\
\text { coordination, 'discomplete- } \\
\text { ness', processing of signals }\end{array}$ & $\mathrm{C} 2-\mathrm{S} 3$ & AIS A-E & $\begin{array}{l}\text { All, qualified: } \\
\text { Participant must } \\
\text { cognitively cooperate }\end{array}$ & $\begin{array}{l}\text { Medications can diminish } \\
\text { responsiveness }\end{array}$ \\
\hline Sympathetic skin responses (SSRs) & $\begin{array}{l}\text { Autonomic sympathetic } \\
\text { outflow }\end{array}$ & C2-S3 & AIS A-E & All & $\begin{array}{l}\text { Further tests required to assess } \\
\text { autonomic function of systems other } \\
\text { than sweat production }\end{array}$ \\
\hline
\end{tabular}

Abbreviations: AIS, American Spinal Injury Association Impairment Scale; SCI, spinal cord injury.

a

\section{Categories Represented for the Imaging CDEs}

- Technical information

- Imaging equipment

- Anatomic region

- Pre-existing hardware

- Exam pulse sequence features

- Spinal injury features

- Vertebral involvement

- Ligamentous involvement

- Degenerative features

- Canal/cord measurements

o Injury extent and length

- Acute SCl features

- Chronic SCl features b

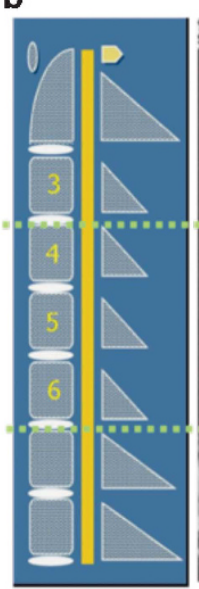

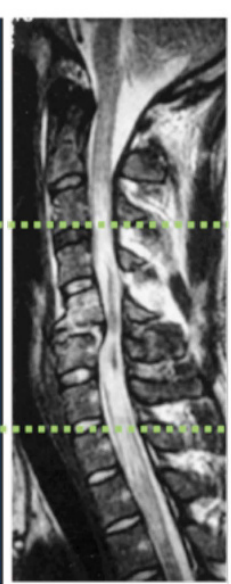

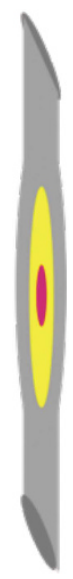

Figure 2 General categories represented with the Imaging common data elements (CDEs). (a) The case report form (CRF) developed for the MRI CDEs includes elements associated with technical and anatomical information. (b) A diagram illustrating the methodology for anatomic localization of spinal cord injury features is included in the CRF. This provides a reproducible method for mapping the location of spinal cord injury features relative to the anatomic spinal level (modified from Flanders et al. ${ }^{55}$ ).

Additional imaging techniques, including some that were considered experimental or under development (for example, computed tomography angiography, magnetic resonance angiogram, magnetization transfer, functional MRI, perfusion imaging,
MR spectroscopy, myelin water fraction and advanced diffusion methods such as diffusion kurtosis imaging), were also discussed. These are listed as Exploratory instruments in Table 2, but CRFs were not created for these. Further guideline documents 
will be posted on the NINDS CDE website as these methods become more widely used.

\section{DISCUSSION}

\section{Implications and use of the NINDS CDEs for SCI}

The NINDS CDEs for SCI (Version 1.0) include over 1150 unique data elements. Whereas some of these were created de novo, many of the SCI CDEs are also used across other domains and diseases. Importantly, the widespread and common use and identification of these data elements with their unique IDs and nomenclature will facilitate sharing of data across a wide range of study types. Furthermore, sharing of IDs and cross-referencing with the ISCoS International SCI Data Sets will enable a common language across the full spectrum of clinical research studies worldwide.

As with all of the NINDS disease areas, the SCI CDEs are intended to be a resource to facilitate developing, designing and writing protocols for any clinical study related to SCI. The CRFs and copyrighted instruments are listed on the NINDS CDE website, and the guidelines and recommendations provided with each of the domains should be consulted to help select and apply the relevant items for a particular project. CRFs from non-copyrighted instruments may be downloaded and used without any charge, whereas links and contact information to obtain necessary permissions or licenses required for copyrighted instruments are provided as needed. Individual CDEs and the SCI-specific CRFs can also be located using a CRF Search tool on the NINDS CDE website. These may be downloaded and assembled to accommodate a wide range of study designs using Form Builder tools and can be easily incorporated into computer entry forms for any study sites with established data collection systems. Note that users are advised to keep the selected format, permissible values and nomenclature for each unique element intact and consistent to enable useful data sharing. Copyrighted instruments may not be altered without consultation with the copyright holders.

While realizing the great advantage of a publically available CDE resource, it is important to caution that the NINDS CDEs are recommendations, but are not intended as definitive requirements for study protocols. The selection of CDEs and reading the associated guidelines cannot substitute for the researchers' own judgment and/or collaborative input from experts with experience in designing clinical studies and those who are familiar with each of the outcome instruments and tools. Specific recommendations for designing clinical trials have been developed by the combined efforts of a number of organizations as part of the International Campaign for Cures of Spinal Cord Injury Paralysis (ICCP). ${ }^{58-60}$

Although the benefits of using the working group consensus approach to develop CDE recommendations are clear, there are also potential limitations of both the process and outcome. The recommendations are based on the current knowledge, experience, and perceptions related to SCI and developed by a subset of all SCI clinical research experts. Some disparate opinions regarding the strength of evidence, the classifications or even the overall ICF framework should be anticipated ${ }^{61}$ and the oversight group is designed to consider open discussion and changes in community perception over time. In addition, the NINDS SCI CDEs are intended to be incorporated and relevant across many neurological diseases and conditions, and hence some SCI-specific concerns must be considered in relation to consistency and general use across the larger CDE project. These issues should be minimized through public input as part of the planned ongoing review process described below.

\section{Navigating the NINDS CDE SCI website}

An introduction to the SCI CDE project can be found on the main screen of the SCI CDE webpage cited above. New users should begin with the resources in the 'Learn' tab that provides a project overview, instructions, glossary, references and more. The WG-recommended CRFs and corresponding guidelines are listed in alphabetical order in each section, and the underlying data element information (' $\mathrm{CDE}$ Details', containing the CDE IDs, definitions, permissible values and so on) or copyright instrument information can be downloaded from the adjacent location. Finally, tabs at the top of the main page can be used to search the CDE or CRF database and to build custom forms for specific study use.

\section{Future developments and gaps}

The NINDS CDEs are intended to provide a stable resource, while enabling incorporation of new instruments and recognizing validation efforts and changes in impact in the field. Continuing review and further modifications of the CDEs or their classifications will occur in time based on user feedback, new developments and validation studies. Thus, researchers and the community must be proactive and provide feedback to the NINDS CDE Project team regarding items that are particularly useful and should be considered for more widespread use, as well as those that should be refined or removed. Those who are developing data archives and sharing platforms should also be aware that modest changes may be made in time, although the goal is to minimize the frequency of extensive revisions in order to maintain the integrity of previously coded data.

During the internal review process, the WG Chairs discussed issues that crossed WG domains as well as gaps in the spectrum of selected CDEs. For example, the use of electrodiagnostics or imaging may be especially informative when applied in combination with particular functional and/or neurological outcomes to reveal information that is lost or cannot be measured using a single approach. An additional issue that has been raised is the need to increase consumer awareness and add relevant input into the CDEs in the ongoing review process. The WGs included nonprofit organization representatives and an active consumer and consumer liaison, but with the online resource now widely available, greater engagement with SCI consumers and advocates is encouraged and quite feasible. With regard to content gaps, a review of the final recommendations has revealed a gap in the identification of CDEs to assess community interactions and caregiver activities and burden. This is also an area where we encourage greater engagement and community feedback. There is also clear agreement that, as in traumatic brain injury, many of the recommendations that are appropriate for use with adults with SCI are not valid or easily translated for use with pediatric SCI study participants. ${ }^{62}$ To address this latter concern, the NINDS CDE team has assembled a new WG to review and develop recommendations for Pediatric SCI clinical studies and will release guidelines for these CDEs within the next year. Finally, the oversight committee is also in the process of reaching out to other SCI data registry sources, many of which had representatives on the WG teams, in order to further define and continue collaborative and shared efforts.

Similar to the reliability testing occurring with the International SCI Data Sets ${ }^{63,64}$ as outlined by Biering-Sørensen et al. ${ }^{65}$ changes to the NINDS CDEs will be based on evidence and reviewed first by experts in the field. In keeping with the established collaborative effort, recommendations for additions or revisions to the NINDS CDEs will be subsequently discussed by the NINDS Oversight Committee in collaboration with the International SCI Data Set Committee to ensure 
continued alignment. Following the first level of review, any significant proposed changes or additions to the CDEs will then be available for public comment, followed by revision before posting on the NINDS CDE website. The NINDS CDE project has committed to review the CDEs at $\sim 6$-month intervals to ensure these are relevant and up to date. As a stable resource, major changes will be considered only after allowing sufficient time (for example, 3 years) for the community to use and test the CDEs in a research environment. All suggestions and recommendations can be submitted directly to the Project Officer or the website project managers by using the CONTACT link at the top of all NINDS CDE web pages.

\section{CONCLUSION}

The NINDS CDEs for SCI clinical research provide a wide-ranging resource for investigators, including common standards and tools, variable names, range checks, permissible values and standard definitions for use across SCI studies. The SCI CDE WGs have volunteered their expertise and time to identify a catalog of CDEs, including informed guidance documents and recommendations for their use, and have assembled and included relevant references that can be used when designing a broad range of clinical studies and trials for SCI. NIH encourages use of the CDEs for all clinical research, patient registries and other human studies. The use of CDEs is not, at present, a requirement for studies; however, researchers receiving funding from NINDS are advised when preparing grant applications to use these CDEs in CRFs and data management systems whenever possible and to incorporate the CDEs into their required data-sharing plans for all clinical research studies and clinical trials.

\section{CONFLICT OF INTEREST}

The authors declare no conflict of interest.

\section{ACKNOWLEDGEMENTS}

The views expressed here are those of the authors and do not represent those of the National Institutes of Health (NIH), the National Institute of Neurological Disorders and Stroke (NINDS) or the US Government. Logistics support for this project was provided in part through NIH Contract

HHSN271201200034C. The development of the NINDS SCI CDEs was made possible thanks to the great investment of time and effort of all organizing committee and WG members and members of the NINDS CDE Project team, participating from 2007 to 2014 .

\section{SCI CDE ORGANIZING COMMITTEE}

Joanne Odenkirchen (NINDS CDE Project Officer): National Institutes of Health/National Institute of Neurological Disorders and Stroke (NIH/NINDS), Bethesda, MD, USA

Naomi Kleitman: NIH/NINDS, Bethesda, MD, USA (2008-2012) and

Craig H. Neilsen Foundation, Encino, CA, USA (2012 to present)

Fin Biering-Sørensen: Department for Spinal Cord Injuries, Rigshospitalet and

Glostrup Hospital, University of Copenhagen, Copenhagen, Denmark

Michael DeVivo: Department of Physical Medicine and Rehabilitation,

University of Alabama at Birmingham, Birmingham, AL, USA

Vanessa Noonan: Rick Hansen Institute, Vancouver, British Columbia, Canada Susan Charlifue: Craig Hospital, Englewood, CO, USA

Linda Jones: Craig H. Neilsen Foundation, Encino, CA, USA (2012 to present)

Lyn Jakeman: NIH/NINDS, Bethesda, MD, USA (2013 to present)

\section{WORKING GROUP MEMBERS}

Demographics $W G$

Yuying Chen (Chair): University of Alabama at Birmingham, Birmingham, AL, USA

Fin Biering-Sørensen: Department for Spinal Cord Injuries, Rigshospitalet and Glostrup Hospital, University of Copenhagen, Copenhagen, Denmark
Susan Charlifue: Craig Hospital, Englewood, CO, USA

Vanessa Noonan: Rick Hansen Institute, Vancouver, British Columbia, Canada

Peter New: Caulfield Hospital, Alfred Health, Caulfield, Victoria, Australia Vanessa Noonan: Rick Hansen Institute, Vancouver, British Columbia, Canada

Marcel Post: University Medical Center Utrecht and De Hoogstraat, The Netherlands

Care $W G$

Vanessa Noonan (Chair): Rick Hansen Institute, Vancouver, British Columbia, Canada

David Berlowitz: Victorian Respiratory Support Service Department of Respiratory and Sleep Medicine, Melbourne, Australia

Fin Biering-Sørensen: Department for Spinal Cord Injuries, Rigshospitalet and

Glostrup Hospital, University of Copenhagen, Copenhagen, Denmark

James S Harrop: Jefferson Medical College, Philadelphia, PA, USA

Michael Fehlings: Toronto Western Hospital, Toronto, Ontario, Canada

David W Wright: Emory University School of Medicine, Atlanta, GA, USA

Neurological outcomes WG

John Steeves (Chair): University of British Columbia and Vancouver Coastal

Health, Vancouver, British Columbia, Canada

Andrew R. Blight: Acorda Therapeutics, Inc., Ardsley, NY, USA

Armin Curt: University of Zurich, University Hospital Balgrist, Zurich,

Switzerland

Linda Jones: Craig H. Neilsen Foundation, Encino, CA, USA

Daniel P Lammertse: Craig Hospital, Englewood, CO, USA

Keith Tansey: Emory University and VA Medical Center, Atlanta, GA, USA

Functional outcomes WG

Kim Anderson-Erisman (Chair): The Miami Project to Cure Paralysis, Miami, FL, USA

Andrea L Behrman: Kentucky Spinal Cord Injury Research Center, University of Louisville, Louisville, KY, USA

Edelle Field-Fote: University of Miami Miller School of Medicine, Miami,

FL, USA

Linda Jones: Craig H. Neilsen Foundation, Encino, CA, USA

MJ Mulcahey: Thomas Jefferson University, Philadelphia, PA, USA

Participation/QOL WG

Susan Charlifue (Chair): Craig Hospital, Englewood, CO, USA

Allen W Heinemann: Northwestern University, Chicago, IL, USA

Alan M Jette: Health \& Disability Research Institute, Boston University, Boston, MA, USA

Marcel Post: University Medical Center Utrecht and De Hoogstraat,

The Netherlands

Denise G Tate: University of Michigan Medical School, Ann Arbor, MI, USA

David S Tulsky: University of Michigan Medical School, Ann Arbor, MI, USA Gale Whiteneck: Craig Hospital, Englewood, CO, USA

Electrodiagnostics WG

Keith Tansey (Chair): Emory University and VA Medical Center, Atlanta, GA, USA

Peter Ellaway: Imperial College of London, London, UK

Keith C Hayes: The University of Western Ontario, London, Ontario, Canada

John Kramer: Shepherd Center, Atlanta, GA, USA

Barry McKay: Shepherd Center, Atlanta, GA, USA

Martin Schubert: Balgrist University Hospital, Zurich, Switzerland

Arthur M Sherwood: Baylor College of Medicine, Houston, TX, USA

Imaging $W G$

Adam E. Flanders (Chair): Thomas Jefferson University Hospital, Philadelphia,

PA, USA,

David Dungan: Radiology Imaging, Associates, PC, Englewood, CO, USA

Ralph F Frankowski: University of Texas Health Science Center at Houston,

School of Public Health, Houston, TX, USA

Daniel P Lammertse: Craig Hospital, Englewood, CO, USA

Edward D Wirth III: Asterias Biotherapeutics, Menlo Park, CA, USA 
Pain WG and Psychological outcomes WG

Eva Widerström-Noga (Chair): University of Miami, Miller School of Medicine, Miami, FL, USA

Charles Bombardier: University of Washington School of Medicine, Seattle, WA, USA

Thomas N Bryce: University of Miami Miller School of Medicine, New York, NY, USA

Nanna Finnerup: Aarhus University Hospital, Aarhus, Denmark

Paul Kennedy: The Oxford Institute of Clinical Psychology Training, Oxford, UK

Mark Jensen: University of Washington, Seattle, WA, USA

John Kramer: Shepherd Center, Atlanta, GA, USA

Philip Siddall: Kolling Institute of Medical Research, The University of Sydney,

Sydney, Australia

\section{NINDS CDE Team}

Joanne Odenkirchen: NINDS CDE Project Officer, National Institutes of Health/National Institute of Neurological Disorders and Stroke (NIH/NINDS), Bethesda, MD, USA

Courtney Ashton: KAI Research, Inc. (an Altarum Company), Rockville, MD, USA (2007-2012)

Stacie Grinnon: KAI Research, Inc. (an Altarum Company), Rockville, MD, USA (2007-2012)

Christina You: KAI Research, Inc. (an Altarum Company), Rockville, MD, USA (2007-2012)

Yun Lu: KAI Research, Inc. (an Altarum Company), Rockville, MD, USA (2007-2012)

Aria Lans: The EMMES Corporation, Rockville, MD, USA (2012 to present) Sherita Ala'i: The EMMES Corporation, Rockville, MD, USA (2012 to present) Naomi Kleitman: Program Director, National Institutes of Health/National Institute of Neurological Disorders and Stroke (NIH/NINDS), Bethesda, MD, USA (2007-2012)

Lyn Jakeman: Program Director, National Institutes of Health/National Institute of Neurological Disorders and Stroke (NIH/NINDS), Bethesda, MD, USA (2013 to present)

1 Groft SC, Rubinstein YR. New and evolving rare diseases research programs at the National Institutes of Health. Public Health Genomics 2013; 16: 259-267.

2 Nadkarni PM, Brandt CA. The common data elements for cancer research: remarks on functions and structure. Methods Inf Med 2006; 45: 594-601.

3 Pathak J, Wang J, Kashyap S, Basford M, Li R, Masys DR et al. Mapping clinical phenotype data elements to standardized metadata repositories and controlled terminologies: the eMERGE Network experience. J Am Med Inform Assoc 2011; 18 376-386.

4 Warzel DB, Andonaydis C, McCurry B, Chilukuri R, Ishmukhamedov S, Covitz P. Common data element (CDE) management and deployment in clinical trials. AMIA Annu Symp Proc 2003; 2003: 1048.

5 Grinnon ST, Miller K, Marler JR, Lu Y, Stout A, Odenkirchen J et al. National Institute of Neurological Disorders and Stroke Common Data Element project - approach and methods. Clin Trials 2012; 9: 322-329.

6 Maas Al, Harrison-Felix CL, Menon D, Adelson PD, Balkin T, Bullock R et al. Standardizing data collection in traumatic brain injury. J Neurotrauma 2011; 28: 177-187.

7 Hicks R, Giacino J, Harrison-Felix CL, Manley GT, Valadka A, Wilde EA. Progress in developing common data elements for traumatic brain injury research: version two-the end of the beginning. J Neurotrauma. 2013; 30: 1852-1861.

8 Saver JL, Warach S, Janis S, Odenkirchen J, Becker K, Benavente 0 et al., for the NINDS Common Data Element Working Group. Standardizing the structure of stroke clinical and epidemiological research data: the NINDS Stroke Common Data Element (CDE) Project. Stroke 2012; 43: 967-973.

9 Loring D, Lowenstein D, Barbaro N, Fureman B, Odenkirchen J, Jacobs M et al. Common data elements in epilepsy research: development and implementation of the NINDS epilepsy CDE project. Epilepsia 2011; 52: 1186-1191.

10 Sherman AV, Gubitz AK, Al-Chalabi A, Bedlack R, Berry J, Conwit R et al. Infrastructure resources for clinical research in amyotrophic lateral sclerosis. Amyotroph Lateral Scler Frontotemporal Degener 2013; 14: 53-61.

11 Lynch DR, Pandolfo M, Schulz JB, Perlman S, Delatycki MB, Payne RM et al. Common data elements for clinical research in Friedreich's ataxia. Mov Disord 2013; 28: 1-5.

12 Biering-Sørensen F, Charlifue S, DeVivo M, Noonan V, Post M, Stripling T, Wing P. International spinal cord injury data sets. Spinal Cord 2006; 44: 530-534.

13 Biering-Sørensen F, Charlifue S, DeVivo MJ, Grinnon ST, Kleitman N, Lu Y et al. Using the spinal cord injury common data elements. Top Spinal Cord Inj Rehabil 2012; 18: 23-27.
14 Biering-Sørensen F, Charlifue S, Devivo MJ, Grinnon ST, Kleitman N, Lu Y et al. Incorporation of the International Spinal Cord Injury Data Set elements into the National Institute of Neurological Disorders and Stroke Common Data Elements. J Spinal Cord 2011; 49: 60-64.

15 Kostanjsek N. Use of The International Classification of Functioning, Disability and Health (ICF) as a conceptual framework and common language for disability statistics and health information systems. BMC Public Health 2011; 11: S3.

16 DeVivo M, Biering-Sørensen F, Charlifue S, Noonan V, Post M, Stripling T et al. International spinal cord injury core data set. Spinal Cord 2006; 44: 535-540.

17 Krassioukov A, Alexander MS, Karlsson AK, Donovan W, Mathias CJ, Biering-Sørensen F. International spinal cord injury cardiovascular function basic data set. Spinal Cord 2010; 48: 586-590.

18 Biering-Sørensen F, Krassioukov A, Alexander MS, Donovan W, Karlsson AK, Mueller G et al. International spinal cord injury pulmonary function basic data set. Spinal Cord 2012; 50: 418-421.

19 Bauman WA, Biering-Sørensen F, Krassioukov A. International spinal cord injury endocrine and metabolic basic data set (version 1.2). Spinal Cord 2012; 50: 567.

20 Biering-Sørensen F, Burns AS, Curt A, Harvey LA, Jane Mulcahey M, Nance PW et al. International spinal cord injury musculoskeletal basic data set. Spinal Cord 2012; 50: 797-802.

21 Biering-Sørensen F, Craggs M, Kennelly M, Schick E, Wyndaele JJ. International spinal cord injury lower urinary tract function basic data set. Spinal Cord 2008; 46: 325-330.

22 Krogh K, Perkash I, Stiens SA, Biering-Sørensen F. International spinal cord injury bowel function basic data set. Spinal Cord 2009; 47: 230-234.

23 New PW, Marshall R. International spinal cord injury data sets for non-traumatic spinal cord injury. Spinal Cord 2014; 52: 123-132.

24 Dvorak MF, Wing PC, Fehlings MG, Vaccaro AR, Itshayek E, Biering-Sorensen F et al. International spinal cord injury spinal column injury basic data set. Spinal Cord 2012; 50: 817-821.

25 Goetz LL, Cardenas DD, Kennelly M, Bonne Lee BS, Linsenmeyer T, Moser C et al. International spinal cord injury urinary tract infection basic data set. Spinal Cord 2013; 51: 700-704.

26 Karlsson AK, Krassioukov A, Alexander MS, Donovan W, Biering-Sørensen F. International spinal cord injury skin and thermoregulation function basic data set. Spinal Cord 2012; 50: 512-516.

27 Alexander MS, Biering-Sørensen F, Elliott S, Kreuter M, Sønksen J. International spinal cord injury male sexual function basic data set. Spinal Cord 2011; 49: 795-798.

28 Alexander MS, Biering-Sørensen F, Elliott S, Kreuter M, Sønksen J. International spinal cord injury female sexual and reproductive function basic data set. Spinal Cord 2011; 49: 787-790.

29 Krogh K, Perkash I, Stiens SA, Biering-Sørensen F. International bowel function extended data set. Spinal Cord 2009; 47: 235-241.

30 Biering-Sørensen F, Craggs M, Kennelly M, Schick E, Wyndaele J-J. International urinary tract imaging basic spinal cord injury data set. Spinal Cord 2009; 47: 379-383.

31 Biering-Sørensen F, Craggs M, Kennelly M, Schick E, Wyndaele JJ. International spina cord injury urodynamic basic data set. Spinal Cord 2008; 46: 513-516.

32 Dvorak MF, Itshayek E, Fehlings MG, Vaccaro AR, Wing PC, Biering-Sorensen F et al International spinal cord injury spinal interventions and surgical procedures basic data set. Spinal Cord 2015; 53: 155-165.

33 Biering-Sørensen F, Bryden A, Curt A, Friden J, Harvey LA, Mulcahey MJ et al. International spinal cord injury upper extremity basic data set. Spinal Cord 2014; 52: 652-657.

34 Gassaway J, Whiteneck G, Dijkers M. Clinical taxonomy development and application in spinal cord injury research: the SCIRehab Project. J Spinal Cord Med 2009; 32: 260-269.

35 Kirshblum SC, Waring W, Biering-Sorensen F, Burns SP, Johansen M, Schmidt-Read M et al. Reference for the revision of the International Standards for Neurological Classification of Spinal Cord Injury. J Spinal Cord Med 2011; 34: 547-554.

36 Charlifue S, Post MW, Biering-Sørensen F, Catz A, Dijkers M, Geyh S et al. International spinal cord injury quality of life basic data set. Spinal Cord 2012; 50: 672-675.

37 Widerström-Noga E, Biering-Sørensen F, Bryce TN, Cardenas DD, Finnerup NB, Jensen MP et al. The international spinal cord injury pain basic data set (version 2.0). Spinal Cord 2014; 52: 282-286.

38 DeVivo MJ, Go BK, Jackson AB. Overview of the national spinal cord injury statistica center database. J Spinal Cord Med 2002; 25: 335-338.

39 Devivo MJ. Epidemiology of traumatic spinal cord injury: trends and future implications. Spinal Cord 2012; 50: 365-372.

40 Noonan VK, Kwon BK, Soril L, Fehlings MG, Hurlbert RJ, Townson A et al. RHSCIR Network. The Rick Hansen Spinal Cord Injury Registry (RHSCIR): a national patientregistry.. Spinal Cord 2012; 50: 22-27.

41 Grossman RG, Toups EG, Frankowski RF, Burau KD, Howley S. North American Clinical Trials Network for the Treatment of Spinal Cord Injury: goals and progress. J Neurosurg Spine 2012; 17: 6-10.

42 Steeves JD, Lammertse D, Curt A, Fawcett JW, Tuszynski MH, Ditunno JF et al. Guidelines for the conduct of clinical trials for spinal cord injury (SCI) as developed by the ICCP panel: clinical trial outcome measures. Spinal Cord 2007; 45: 206-221.

43 Steeves JD, Lammertse DP, Kramer JL, Kleitman N, Kalsi-Ryan S, Jones L et al. Outcome Measures for Acute/Subacute Cervical Sensorimotor Complete (AIS-A) Spinal Cord Injury During a Phase 2 Clinical Trial. Top Spinal Cord Inj Rehabil 2012; 18 $1-14$. 
44 Kramer JKL, Lammertse DP, Schubert M, Curt A, Steeves JD. Relationship between motor recovery and independence after sensorimotor complete cervical spinal cord injury. Neurorehabil Neural Repair 2012; 26: 1064-1071.

45 Lammertse DP, Jones LA, Charlifue SB, Kirshblum SC, Apple DF, Ragnarsson KT et al. Autologous incubated macrophage therapy in acute, complete spinal cord injury: results of the phase 2 randomized controlled multicenter trial. Spinal Cord 2012; 50: 661-671.

46 Hallett M. NINDS myotatic reflex scale. Neurology 1993; 43: 2723.

47 Gershon RC1, Rothrock N, Hanrahan R, Bass M, Cella D. The use of PROMIS and assessment center to deliver patient-reported outcome measures in clinical research. J Appl Meas 2010; 1: 304-314.

48 Cella D, Nowinski C, Peterman A, Victorson D, Miller D, Lai JS et al. The neurology quality of life measurement initiative. Arch Phys Med Rehabil 2011; 92: S28-S36.

49 Tulsky DS1, Kisala PA, Victorson D, Tate D, Heinemann AW, Amtmann D et al. Developing a contemporary patient-reported outcomes measure for spinal cord injury. Arch Phys Med Rehabil 2011; 92: S44-S51.

50 Bryce TN, Biering-Sorensen F, Finnerup NB, Cardenas DD, Defrin R, Lundeberg T et al. International Spinal Cord Injury Pain (ISCIP) classification: part I. Background and description. Spinal Cord 2012; 50: 413-417.

51 Bryce TN, Biering-Sorensen F, Finnerup NB, Cardenas DD, Defrin R, Ivan E et al. International Spinal Cord Injury Pain (ISCIP) classification: part 2. Initial validation using vignettes. Spinal Cord 2012; 50: 404-412.

52 Kennedy P, Lude P, Elfström ML, Smithson E. Cognitive appraisals, coping and quality of life outcomes: a multi-centre study of spinal cord injury rehabilitation. Spinal Cord 2010; 48: 762-769.

53 Bombardier CH, Richard JS, Krause JS, Tulsky D, Tate DG. Symptoms of major depression in people with spinal cord injury: implications for screening. Arch Phys Med Rehabil 2004; 95: 1749-1756.

54 Bombardier CH, Kalpakjan CZ, Graves DE, Dyer JR, Tate DG, Fann JR. Validity of the Patient Health Questionnaire - 9 in assessing major depressive disorder during inpatient spinal cord injury rehabilitation. Arch Phys Med Rehabil 2012; 93: 1838-1845.

55 Flanders AE, Spettell CM, Tartaglino LM, Friedman DP, Herbison GJ. Forecasting motor recovery after cervical spinal cord injury: value of MR imaging. Radiology 1996; 201: $649-655$.
56 Furlan JC, Fehlings MG, Massicotte EM, Aarabi B, Vaccaro AR, Bono CM et al. A quantitative and reproducible method to assess cord compression and canal stenosis after cervical spine trauma: a study of interrater and intrarater reliability. Spine 2007; 32: 2083-2091.

57 Shanmuganathan K, Gullapalli, Zhuo J, Mirvis SE. Diffusion tensor MR imaging in cervical spine trauma. AJNR Am J Neuroradiol 2008; 29: 655-659.

58 Lammertse D, Tuszynski MH, Steeves JD, Curt A, Fawcett JW, Rask C et al. Guidelines for the conduct of clinical trials for spinal cord injury ( $\mathrm{SCI}$ ) as developed by the ICCP panel: clinical trial design. Spinal Cord 2007; 45: 232-242.

59 Tuszynski MH, Steeves JD, Fawcett JW, Lammertse D, Kalichman M, Rask C et al. Guidelines for the conduct of clinical trials for spinal cord injury (SCI) as developed by the ICCP panel: clinical trial inclusion/exclusion criteria and ethics. Spinal Cord 2007; 45: 222-231.

60 Fawcett JW, Curt A, Steeves JD, Coleman WP, Tuszynski MH, Lammertse D et al. Guidelines for the conduct of clinical trials for spinal cord injury $(\mathrm{SCl})$ as developed by the ICCP panel: spontaneous recovery after spinal cord injury and statistical power needed for therapeutic clinical trials. Spinal Cord 2007; 45: 190-205.

61 Ptyushkin P, Vidmar G, Burger H, Marincek C. Use of the International Classification of Functioning, Disability, and Health in traumatic brain injury rehabilitation: linking issues and general perspectives. Am J Phys Med Rehabil 2012; 91: S48-S54.

62 Miller AC, Odenkirchen J, Duhaime AC, Hicks R. Common data elements for research on traumatic brain injury: pediatric considerations. J Neurotrauma 2012; 29: 621-628.

63 Jensen MP, Widerström-Noga E, Richards JS, Finnerup NB, Biering-Sørensen F, Cardenas DD. Reliability and validity of the International Spinal Cord Injury Basic Pain Data Set items as self-report measures. Spinal Cord 2010; 48: 230-238.

64 Juul T, Bazzocchi G, Coggrave M, Johannesen IL, Hansen RB, Thiyagarajan C et al. Reliability of the international spinal cord injury bowel function basic and extended data sets. Spinal Cord 2011; 49: 886-891.

65 Biering-Sørensen F, Alexander MS, Burns S, Charlifue S, Devivo M, Dietz V et al. Recommendations for translation and reliability testing of international spinal cord injury data sets. Spinal Cord 2011; 49: 357-360. 